\title{
Drug Prescription in Older Swiss Men and Women Followed in Family Medicine
}

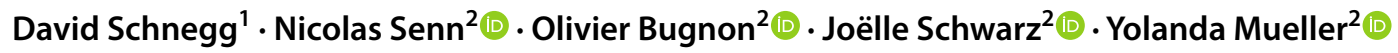

Published online: 17 December 2019

(c) The Author(s) 2019

\begin{abstract}
Background We sought to estimate the prevalence of polypharmacy, the most prevalent drug classes involved, and the prevalence and type of potentially inappropriate prescribing among older male and female patients in family medicine.

Methods We conducted a secondary analysis of baseline data from a pragmatic cluster-randomised trial on the efficacy of a screening and management tool for geriatric syndromes among older community-dwelling patients (aged $\geq 75$ years) included by 42 family physicians. Information on drug prescription and clinical diagnoses (International Classification of Primary Care-2nd Edition [ICPC-2] coded) were extracted manually from medical records. The prevalence of polypharmacy, defined as the use of at least five permanent oral or parenteral drugs, and of potentially inappropriate medications (PIMs), identified according to 2015 updated Beers criteria, were compared between men and women.

Results We included 429 patients (269 women and 160 men; mean age 82.9 and 81.8 years, respectively). Polypharmacy was found in $59.9 \%$ of them. Analgesics, antithrombotic agents and agents acting on the renin-angiotensin system were the most frequently prescribed drug categories. Three-quarters of patients (76.7\%) were prescribed at least one PIM according to Beers criteria, without difference by sex/gender $(p=0.760)$. The most frequent PIMs were proton-pump inhibitors used for $>8$ weeks, diuretics, benzodiazepines, aspirin for primary prevention, and chronic use of non-steroidal anti-inflammatory drugs. Prescription patterns markedly differed by sex/gender, but the number and patterns of inappropriate prescriptions were comparable overall.

Interpretation Both polypharmacy and PIMs were very common in older patients followed regularly in family medicine in Switzerland. Interestingly, most PIMs involved only a limited number of medication classes.
\end{abstract}

Trial registration Clinicaltrials.gov NCT 02618291.

\section{Introduction}

Polypharmacy and inappropriate prescribing are important clinical challenges, especially among older patients, who often have multiple chronic conditions. Polypharmacy is heterogeneously defined in studies as the use of multiple medications by the patient, although most studies agree on a threshold of at least five medications [1]. In

Electronic supplementary material The online version of this article (https://doi.org/10.1007/s40801-019-00175-6) contains supplementary material, which is available to authorized users.

Yolanda Mueller

Yolanda.mueller@unisante.ch

1 University of Lausanne, Lausanne, Switzerland

2 Department of Family Medicine/Center for Primary Care and Public Health (Unisanté), University of Lausanne, Lausanne, Switzerland
Switzerland, one-quarter of community-dwelling patients aged $>65$ years self-report taking five or more drugs [2], although higher rates have been reported based on claims data [3, 4].

Polypharmacy is associated with potentially inappropriate medications (PIMs) [5]. The prevalence of PIM varies according to age, context (community dwelling vs. care home) and the criteria used to define it [6-8]. Swiss data in community-dwelling patients aged $>65$ years reported a prevalence of PIM around $20 \%$ [3, 9, 10], increasing to $74 \%$ in nursing home residents [4]. However, these studies were limited to claims data or conducted in specific populations, and clinical information to estimate inappropriate prescribing was often weak. The most prevalent classes of PIM were psycholeptic agents, followed by sex hormones and genital system modulators, psychoanaleptics, anti-inflammatory and anti-rheumatic products and cardiac therapy [3]. Still, detailed data on prescriptions patterns, polypharmacy and PIM remain 


\section{Key Points}

Older patients, both male and female, followed in family medicine are prescribed a high number of drugs, but different drug classes are prescribed to older men than to older women.

Potentially inappropriate prescribing is very common in both older men and older women.

Most potentially inappropriate medications are concentrated among a few drug classes.

Targeted deprescription advice, differentiated by sex/ gender and focusing on the most prevalent drug classes, could simplify deprescribing for family physicians.

limited in Switzerland, especially for patients followedup in family medicine.

Sex/gender differences have been reported in the prevalence of both polypharmacy and PIM. In the adult population, men are prescribed fewer drugs than are women, even after excluding sex/gender-related morbidity, although the difference decreases with age [11]. Among older populations, evidence on gender difference in polypharmacy varies, but older women seem to receive more PIMs [8, 12-14]. When studies do report gender differences, they most often lack further exploration or explanation of the gender discrepancy. Hofer-Dückelmann [15] explored the reasons for higher rates of polypharmacy in older women, highlighting the gendered differences in attitudes towards drug intake: the female propensity to see a physician and discuss problems, family responsibility and caregiving activities, provider-patient relationship, education, social deprivation and self-rated health. Differences in drug prescriptions have been studied in the field of cardiovascular prevention, with a Swedish study observing that older women were more likely to be treated with diuretics and nitro-glycerine, whereas older men with diabetes were more likely to receive antihyperglycaemic drugs [16]. Other studies have shown that older women receive more psychotropic medications [17-19]. Until now, sex/gender differences in drug prescriptions have not been explored in the Swiss context.

This study aims to provide insight into drug prescription patterns in male and female older patients followed in family medicine in the French-speaking part of Switzerland. The objectives were to estimate the prevalence of polypharmacy, the most prevalent drug classes, the prevalence of PIM and type and, last, the association between polypharmacy/PIMs and the sex/gender of patients.

\section{Method}

\subsection{Study Design}

We conducted a secondary analysis of baseline data from a pragmatic cluster-randomised trial on the efficacy of a screening and management tool for geriatric syndromes in family medicine (NCT 02618291). In this trial, 42 private family medicine practices in western Switzerland, selected according to their willingness to participate in the trial, included at least ten community-dwelling patients (aged $\geq 75$ years), randomly selected among routinely followed patients (at least two visits in the past year) between September 2016 and January 2018.

\subsection{Drug Use and Clinical Information}

Information on drug prescription and clinical diagnosis was extracted manually from paper or electronic medical records by a trained research assistant and entered into a standardised and pretested case report form. Designation was matched with corresponding anatomical therapeutic chemical (ATC) code classification [20] using a predefined list of 2628 drugs that were commercially available in Switzerland. Drugs were categorised in the corresponding second-level ATC class. Only oral or parenteral drugs were considered for this analysis. We distinguished drugs taken continuously from occasional medication based on the information recorded as comments in the case report form. For example, mentions of "stand-by treatment", conditional use ("in case of") and limited time ("until") were considered occasional treatment. Continuous use was considered the default prescription in the absence of comments. Patients' chronic conditions present in the medical file were coded by the same study staff according to a predefined list of 75 diagnoses based on International Classification of Primary Care-2nd Edition (ICPC-2; Wonca International Classification Committee) [21]. Polypharmacy was defined as the prescription of at least five permanent oral or parenteral drugs [22].

\subsection{Potentially Inappropriate Medications (PIMs)}

PIMs were identified and divided into five sections according to 2015 updated Beers criteria [6] using the ICPC-2 diagnosis and ATC classification: medication to avoid in most older patients; drug-disease or drug-syndrome interactions; drugs to be used with caution in older patients; drug-drug interactions meaningful in a geriatric setting; and, finally, drugs that should be avoided or the dose reduced with impaired renal function. The last two sections were added with the 2015 update, so only the first three sections 
were used to assess the total number of PIMs to enable comparison with previous studies.

\subsection{Sex/Gender}

Patient sex/gender categorisation was based on the information available in the medical record as recorded by the physician. Because we could not disentangle the effects of sex (understood as biological characteristics) and gender (socially constructed), we refer to the combined effect of sex/gender [23, 24].

\subsection{Data Analysis}

A Wilcoxon rank-sum test was used to assess whether a difference existed in the number of medications between men and women. Proportions by sex/gender were compared with Chi squared and Fisher's exact tests. We used logistic regression to estimate the odds ratios (ORs) of the prescription of different drug classes by sex/gender. Considering that patients were recruited via their physicians, we used a mixed logistic regression model with a random intercept by physician to adjust the ORs and compared the added value of adding the random intercept by likelihood ratio tests. $p$ values $<0.05$ were considered significant. Stata software (version 14, College Station, TX, USA) was used to analyse the data.

\section{Results}

In total, 42 general practitioners (18 women, 24 men) participated in the trial, each enrolling a median number of 11 patients (interquartile range [IQR] 7-12). Final data consisted of 429 patients with a median age of 82 years (IQR $78-86), 62.7 \%$ of whom were female. Table 1 lists the sociodemographic and clinical characteristics of the included patients. Women were slightly older ( 82.9 vs. 81.8 years; $p=0.021)$ and were more frequently living on their own (64.8 vs. $26.4 \% ; p<0.001)$, receiving home-based care ( 21.3 vs. $11.3 \% ; p=0.009)$, had a lower education level $(p<0.001)$ and were less likely to drive $(35.9$ vs. $76.9 \%$; $p<0.001)$. The number of ICPC-2 diagnoses was comparable between men and women $(p=0.194)$. The proportion of men, compared with women, with at least one condition reported by ICPC- 2 chapter was comparable for most chapters, with the exception of eye conditions (14.1 vs. $25.6 \%$; $p=0.003$ ), musculoskeletal conditions (66.9 vs. $42.5 \%$; $p<0.001)$ and conditions of the genital system (14.1 vs. $34.4 \% ; p<0.001)$.

\subsection{Polypharmacy and Drug Classes by Sex/Gender}

Patients were prescribed a median of seven drugs (IQR 5-10), or five drugs (IQR 3-8) when occasional medication was excluded, with no differences between men and women ( $p=0.469$ and $p=0.636$, respectively; data not shown). The prevalence of polypharmacy (defined as at least five permanent drugs) was $59.9 \%$ (61.9\% in men; $58.7 \%$ in women; $p=0.521)$. Table 2 lists the most frequent drug classes used. Analgesics and antithrombotic agents were prescribed to more than one-half of patients. Agents acting on the renin-angiotensin system (48.7\%), mineral supplements (44.3\%) and lipidmodifying agents (39.9\%) were the next most frequent drug classes, followed by psycholeptics $(26.6 \%)$ and drugs for acidrelated disorders (26.3\%). Women were more likely to be prescribed mineral supplements (54.3 vs. $27.5 \%$; OR 3.12 [95\% confidence interval $\{\mathrm{CI}\} 2.05-4.77])$, psychoanaleptics (28.3 vs. 16.9\%; OR 1.94 [95\% CI 1.19-3.17]) and thyroid therapy (16.0 vs. 5.6\%; OR 3.37 [95\% CI 1.60-7.10]), whereas men received more prescriptions for antithrombotic drugs (62.5 vs. 43.1\%; OR 0.45 [95\% CI 0.30-0.68]), lipid-modifying agents (49.4 vs. $34.2 \%$; OR 0.53 [95\% CI 0.36-0.79]), urologicals (24.4 vs. 5.6\%; OR 0.18 [95\% CI $0.10-0.35]$ ) and drugs used in diabetes (19.4 vs. $10.0 \%$; OR 0.46 [95\% CI 0.27-0.81]). Four drug classes were frequently prescribed for intermittent use: analgesics, psycholeptics, anti-inflammatory and antirheumatic products and drugs for constipation. A significant variation of the prescription by physician, estimated by adding a random intercept in the model, was found for agents acting on the renin-angiotensin system $(p=0.007)$, lipid-modifying agents $(p<0.001), \beta$-blocking agents $(p=0.027)$ and vitamins $(p<0.001)$.

\subsection{PIM and Sex/Gender}

The percentage of patients with at least one PIM was $76.7 \%$, with a median number of two PIMs per patient (IQR 1-3). Table 3 lists the ten most prevalent PIMs, representing $93.8 \%$ of all identified PIMs, along with the rationale for the recommendation. The most frequent medications to avoid for most older adults were proton-pump inhibitors (PPIs) prescribed for a duration $>8$ weeks ( $23.1 \%$ of patients), benzodiazepines (21.5\%), chronic use of oral non-cyclooxygenase-selective non-steroidal anti-inflammatory drugs (NSAIDs) (16.8\%) and nonbenzodiazepine/benzodiazepine receptor agonist hypnotics $(9.8 \%)$. The most frequent drugs that should be used with caution in most older adults included diuretics (28.4\% of patients), aspirin for primary prevention of cardiac events (19.8\%), vasodilators $(15.8 \%)$ and selective serotonin reuptake inhibitors (SSRIs) (12.4\%).

Details of all PIMs and comparison by sex/gender can be found in Table 1 in the Electronic Supplementary 
Table 1 Sociodemographic and clinical characteristics

\begin{tabular}{|c|c|c|c|}
\hline Characteristic & Women $(N=269)$ & $\operatorname{Men}(N=160)$ & $P$ value \\
\hline Age (years) & $82.9 \pm 5.2$ & $81.8 \pm 4.5$ & 0.021 \\
\hline Living alone & $169(64.5)(N=262)$ & $42(26.3)(N=160)$ & $<0.001$ \\
\hline Driving a car & $95(35.9)(N=265)$ & $123(76.9)(N=160)$ & $<0.001$ \\
\hline Receiving home-based care & $57(21.2)(N=269)$ & $18(11.3)(N=160)$ & 0.009 \\
\hline \multirow[t]{2}{*}{ Receiving help from other caregivers } & $64(25.3)(N=253)$ & $24(16.0)(N=150)$ & 0.029 \\
\hline & $N=249$ & $N=149$ & \\
\hline Education (degree reached) & & & $<0.001$ \\
\hline Did not finish primary school & $7(2.8)$ & $0(0.0)$ & \\
\hline Primary school & $85(34.1)$ & $28(18.8)$ & \\
\hline Secondary school & $42(16.9)$ & $11(7.4)$ & \\
\hline Professional degree & $86(34.5)$ & $57(38.3)$ & \\
\hline \multirow[t]{2}{*}{ Higher education (university or equivalent) } & $29(11.7)$ & $53(35.6)$ & \\
\hline & $N=269$ & $N=160$ & \\
\hline Median (interquartile range) number of chronic conditions & $4(2-5)$ & $4(3-6)$ & 0.194 \\
\hline \multicolumn{4}{|l|}{ Chronic conditions by ICPC- $2 *$ chapter } \\
\hline General & $17(6.3)$ & $8(5.0)$ & 0.573 \\
\hline Blood & $34(12.6)$ & $22(13.8)$ & 0.741 \\
\hline Digestive system & $77(28.6)$ & $47(29.4)$ & 0.868 \\
\hline Eye & $38(14.1)$ & $41(25.6)$ & 0.003 \\
\hline Ear & $34(12.6)$ & $23(14.4)$ & 0.609 \\
\hline Cardiovascular & $232(86.3)$ & $145(90.6)$ & 0.179 \\
\hline Musculoskeletal & $180(66.9)$ & $68(42.5)$ & $<0.001$ \\
\hline Neurological & $74(27.5)$ & $36(22.5)$ & 0.251 \\
\hline Psychological & $87(32.3)$ & $53(33.1)$ & 0.867 \\
\hline Respiratory & $38(14.1)$ & $33(20.6)$ & 0.080 \\
\hline Skin & $44(16.4)$ & $26(16.3)$ & 0.977 \\
\hline Endocrine/metabolic and nutritional & $125(46.5)$ & $66(41.3)$ & 0.293 \\
\hline Urological & 75 (27.9) & $43(26.9)$ & 0.821 \\
\hline Genital & $38(14.1)$ & $55(34.4)$ & $<0.001$ \\
\hline
\end{tabular}

Data are presented as mean \pm standard deviation or $N(\%)$ unless otherwise indicated

*ICPC International Classification of Primary Care-2nd Edition; Wonca International Classification Committee

Material. Combined, the number of PIMs and proportions of patients with at least one PIM or with different PIM categories were comparable between men and women (at least one PIM: 76.2 vs. $77.5 \%$; $p=0.760$ ). Sex/gender differences were observed in terms of medication categories. The more frequent PIMs in women were antidepressants that should be avoided ( 4.5 vs. $0 \% ; p=0.010$ ), SSRIs to be used with caution ( 15.6 vs. $6.9 \% ; p=0.008)$ and various psychotropic drugs to be avoided in patients with a history of fracture (4.5 vs. $0.6 \% ; p=0.025)$. PIMs more frequent in men were vasodilators to be used with caution (20.0 vs. $11.2 \% ; p=0.012$ ).

\section{Discussion}

Polypharmacy was very common in older patients followed regularly in family medicine in Switzerland, with three of five patients taking at least five drugs. Three-quarters of patients were prescribed at least one PIM according to Beers criteria. The most frequent PIMs were PPIs prescribed for a duration $>8$ weeks, diuretics, benzodiazepines, aspirin for primary prevention of cardiac events and chronic use of NSAIDs. Prescription patterns markedly differed by sex/gender, with more PIMs found in women, who were prescribed more psychotropic drugs that should be avoided or used with caution with regards to their age and medical condition (fracture). Variations in prescription by physician were observed for cardiovascular drugs and vitamins. 
Table 2 Oral and parenteral drug classes prescribed to patients aged $\geq 75$ years followed in primary care and included in the study, by sex/gender

\begin{tabular}{|c|c|c|c|c|c|c|c|c|}
\hline \multirow{2}{*}{$\begin{array}{l}\text { Drug } \\
\text { class } \\
\text { (ATC) }\end{array}$} & \multirow[t]{2}{*}{ Class name } & \multirow{2}{*}{$\begin{array}{l}\text { All drugs } \\
\text { (intermittent } \\
\text { use included) } \\
\text { Total users } \\
(N=429)\end{array}$} & \multicolumn{6}{|c|}{ Continuous use only } \\
\hline & & & $\begin{array}{l}\text { Total users } \\
(N=429)\end{array}$ & $\begin{array}{l}\text { Women } \\
(N=269)\end{array}$ & $\operatorname{Men}(N=160)$ & $\mathrm{OR}^{\mathrm{a}}(95 \% \mathrm{CI})$ & $\begin{array}{l}\text { AdjOR }(95 \% \\
\mathrm{CI})\end{array}$ & $\begin{array}{l}p \text { value for } \\
\text { cluster effect }\end{array}$ \\
\hline N02 & Analgesics & $236(55.0)$ & $82(19.1)$ & $54(20.1)$ & $26(16.3)$ & $1.29(0.77-2.17)$ & $\begin{array}{l}1.36(0.79- \\
2.35)\end{array}$ & 0.017 \\
\hline B01 & $\begin{array}{l}\text { Antithrombotic } \\
\text { agents }\end{array}$ & $224(52.2)$ & $217(50.6)$ & $116(43.1)$ & $100(62.5)$ & $0.45(0.30-0.68)$ & $\begin{array}{l}0.45(0.30- \\
0.68)\end{array}$ & 0.436 \\
\hline $\mathrm{C} 09$ & $\begin{array}{l}\text { Agents acting on } \\
\text { the RAS }\end{array}$ & $212(49.4)$ & $209(48.7)$ & $125(46.5)$ & $80(50.0)$ & $0.87(0.59-1.28)$ & $\begin{array}{l}0.84(0.56- \\
1.28)\end{array}$ & 0.007 \\
\hline A12 & $\begin{array}{l}\text { Mineral supple- } \\
\text { ments }\end{array}$ & $194(45.2)$ & $190(44.3)$ & $146(54.3)$ & $44(27.5)$ & $3.13(2.05-4.77)$ & $\begin{array}{l}3.27(2.10- \\
5.08)\end{array}$ & 0.074 \\
\hline C10 & $\begin{array}{l}\text { Lipid-modifying } \\
\text { agents }\end{array}$ & $173(40.3)$ & $171(39.9)$ & $92(34.2)$ & $79(49.4)$ & $0.53(0.36-0.79)$ & $\begin{array}{l}0.49(0.32- \\
0.76)\end{array}$ & $<0.001$ \\
\hline N05 & Psycholeptics & $167(38.9)$ & $114(26.6)$ & 75 (27.9) & $38(23.8)$ & $1.24(0.79-1.95)$ & $\begin{array}{l}1.23(0.78- \\
1.95)\end{array}$ & 0.372 \\
\hline A02 & $\begin{array}{l}\text { Drugs for } \\
\text { acid-related } \\
\text { disorders }\end{array}$ & $145(33.8)$ & $113(26.3)$ & $43(26.9)$ & $69(25.7)$ & $0.94(0.60-1.46)$ & $\begin{array}{l}0.95(0.60- \\
1.51)\end{array}$ & 0.126 \\
\hline $\mathrm{C} 07$ & $\beta$-blocking agents & $134(31.2)$ & $133(31.0)$ & $80(29.7)$ & $53(33.1)$ & $0.85(0.56-1.30)$ & $\begin{array}{l}0.81(0.52- \\
1.26)\end{array}$ & 0.027 \\
\hline M01 & $\begin{array}{l}\text { Anti-inflam- } \\
\text { matory and } \\
\text { antirheumatic } \\
\text { products }\end{array}$ & $113(26.3)$ & $60(14.0)$ & $38(14.1)$ & $22(13.8)$ & $1.03(0.59-1.82)$ & $\begin{array}{l}1.05(0.59- \\
1.88)\end{array}$ & 0.196 \\
\hline N06 & Psychoanaleptics & $109(25.4)$ & $103(24.0)$ & $76(28.3)$ & $27(16.9)$ & $1.94(1.19-3.17)$ & $\begin{array}{l}1.94(1.18- \\
3.17)\end{array}$ & 0.459 \\
\hline $\mathrm{C} 03$ & Diuretics & $101(23.5)$ & $98(22.8)$ & $60(22.3)$ & $38(23.8)$ & $0.92(0.58-1.47)$ & $\begin{array}{l}0.94(0.58- \\
1.51)\end{array}$ & 0.095 \\
\hline A06 & $\begin{array}{l}\text { Drugs for consti- } \\
\text { pation }\end{array}$ & $104(24.2)$ & $57(13.3)$ & $35(13.0)$ & $22(13.8)$ & $0.94(0.53-1.66)$ & $\begin{array}{l}0.94(0.52- \\
1.70)\end{array}$ & 0.113 \\
\hline A11 & Vitamins & $72(16.8)$ & $71(16.6)$ & $47(17.5)$ & $24(15.0)$ & $1.20(0.70-2.05)$ & $\begin{array}{l}1.33(0.73- \\
2.40)\end{array}$ & $<0.001$ \\
\hline C08 & $\mathrm{CCBs}$ & $71(16.6)$ & $65(15.2)$ & 45 (16.7) & $20(12.5)$ & $1.41(0.80-2.48)$ & NA & \\
\hline G04 & Urologicals & $58(13.5)$ & $53(12.4)$ & $15(5.6)$ & $39(24.4)$ & $0.18(0.10-0.35)$ & NA & \\
\hline A 10 & $\begin{array}{l}\text { Drugs used in } \\
\text { diabetes }\end{array}$ & $58(13.5)$ & $58(13.5)$ & $27(10.0)$ & $31(19.4)$ & $0.46(0.27-0.81)$ & NA & \\
\hline H03 & Thyroid therapy & $53(12.4)$ & $52(12.1)$ & $43(16.0)$ & $9(5.6)$ & $3.37(1.60-7.10)$ & $\begin{array}{l}3.51(1.63- \\
7.57)\end{array}$ & 0.115 \\
\hline C01 & Cardiac therapy & $51(11.9)$ & $34(7.9)$ & $20(7.4)$ & $14(8.8)$ & $0.84(0.41-1.71)$ & $\begin{array}{l}0.79(0.37- \\
1.66)\end{array}$ & 0.093 \\
\hline B03 & $\begin{array}{l}\text { Anti-anaemic } \\
\text { preparations }\end{array}$ & $41(9.6)$ & $40(9.3)$ & $16(10.0)$ & $25(9.3)$ & $0.92(0.48-1.78)$ & $\begin{array}{l}1.06(0.50- \\
2.23)\end{array}$ & $<0.001$ \\
\hline $\mathrm{C} 05$ & Vasoprotectives & $36(8.4)$ & $36(8.4)$ & $26(9.7)$ & $7(4.4)$ & $2.34(0.99-5.52)$ & $\begin{array}{l}2.52(1.03- \\
6.16)\end{array}$ & 0.157 \\
\hline M04 & $\begin{array}{l}\text { Antigout prepara- } \\
\text { tions }\end{array}$ & 34 (7.9) & $31(7.2)$ & $13(4.8)$ & 17 (10.6) & $0.43(0.20-0.90)$ & $\begin{array}{l}0.42(0.19- \\
0.90)\end{array}$ & 0.213 \\
\hline
\end{tabular}

Drugs classed according to ATC code, second-level class. Odds ratios of class prescription by sex/gender from a logistic regression model, raw and after adding a random intercept by physician. Restricted to drug classes prescribed to $\geq 10 \%$ of either male or female patients

Bold formatting indicates statistical significance

AdjOr adjusted OR, ATC anatomical therapeutic chemical, $C C B s$ calcium channel blockers, $C I$ confidence interval, $N A$ not applicable: nonconvergence of mixed logistic regression model, $O R$ odds ratio, $R A S$ renin-angiotensin system

${ }^{a}$ Baseline: Men 
Table 3 The ten most prevalent PIMs according to the 2015 updated Beers criteria, and summary of the rationale for the recommendation

\begin{tabular}{|c|c|c|c|}
\hline Beers criteria item & ATC class & $N(\%)$ & Rationale \\
\hline Diuretics & $\mathrm{C} 03$ & $122(28.4)$ & $\begin{array}{l}\text { Use with caution; may exacerbate or cause } \\
\text { SIADH or hyponatraemia }\end{array}$ \\
\hline Proton-pump inhibitors & A02BC & $99(23.1)$ & $\begin{array}{l}\text { Avoid scheduled use for }>8 \text { weeks unless in } \\
\text { high-risk patients }\end{array}$ \\
\hline Benzodiazepines & $\begin{array}{l}\text { N05BA12, N05CD04, N05BA06, } \\
\text { N05BA56, N05BA04, N05CD07, } \\
\text { N05CD05, N05BA05, N05BA02, } \\
\text { N03AE01, N05BA01, N05BA17, } \\
\text { N05CD01, N05CD10 }\end{array}$ & $92(21.5)$ & $\begin{array}{l}\text { Avoid; older adults have increased sensitiv- } \\
\text { ity to benzodiazepines and decreased } \\
\text { metabolism of long-acting agents. In } \\
\text { general, all benzodiazepines increase the } \\
\text { risk of cognitive impairment, delirium, } \\
\text { falls, fractures and motor vehicle crashes } \\
\text { in older adults }\end{array}$ \\
\hline $\begin{array}{l}\text { Aspirin for primary prevention of cardiac } \\
\text { events }\end{array}$ & B01AC & $85(19.8)$ & Use with caution in patients aged $\geq 80$ years \\
\hline $\begin{array}{l}\text { Non-cyclooxygenase-selective NSAIDs, } \\
\text { oral }\end{array}$ & M01A & $71(16.6)$ & $\begin{array}{l}\text { Avoid chronic use, unless other alterna- } \\
\text { tives are not effective and patient can take } \\
\text { gastroprotective agent }\end{array}$ \\
\hline Vasodilators & $\mathrm{C} 01 \mathrm{D}, \mathrm{C} 04, \mathrm{C} 07 \mathrm{~F}$ & $68(15.8)$ & Use with caution, may cause syncope \\
\hline SSRIs & N06AB & $53(12.4)$ & Use with caution, may cause SIADH \\
\hline $\begin{array}{l}\text { Nonbenzodiazepine, benzodiazepine } \\
\text { receptor agonist hypnotics }\end{array}$ & $\begin{array}{l}\text { N05CF04, N05CF01, N05CF02, } \\
\text { N05CF03 }\end{array}$ & $42(9.8)$ & $\begin{array}{l}\text { Avoid; adverse events in older adults such } \\
\text { as delirium, falls, fractures, increased } \\
\text { hospitalisations }\end{array}$ \\
\hline $\begin{array}{l}\text { Cardiovascular (amiodarone, digoxin, } \\
\text { nifedipine with immediate-release, } \\
\text { doxazosin) }\end{array}$ & $\begin{array}{l}\text { C02CA04, C01AA05, C01AA02, } \\
\text { C01AA52, C01AA08, C08CA05, } \\
\text { C08GA01, C08CA55, C07FB03, } \\
\text { C02CA01, C02LE01, G04CA03, } \\
\text { C02AC01, N02CX02, S01EA04, } \\
\text { C02LC01, C02LC51, C02AC0, C02AB, } \\
\text { C02LB, C02AA0, C02LA01, C02LA51, } \\
\text { C02LA71, C02AA52, C01BA03, } \\
\text { C01BD07, C01BD01 }\end{array}$ & $21(4.9)$ & $\begin{array}{l}\text { Amiodarone: avoid as first-line therapy for } \\
\text { AF unless patient has heart failure or left } \\
\text { ventricular hypertrophy. Digoxin: avoid } \\
\text { as first-line therapy for AF. Nifedipine: } \\
\text { avoid, potential for hypotension and risk } \\
\text { of precipitating myocardial ischaemia. } \\
\text { Doxazosin: avoid as antihypertensive, risk } \\
\text { of orthostatic hypotension }\end{array}$ \\
\hline $\begin{array}{l}\text { Association of chronic kidney disease and } \\
\text { NSAIDs }\end{array}$ & M01A & $21(4.9)$ & $\begin{array}{l}\text { Avoid; may increase risk of acute kidney } \\
\text { injury and further decline of renal func- } \\
\text { tion }\end{array}$ \\
\hline
\end{tabular}

$A F$ atrial fibrillation, ATC anatomical therapeutic chemical, PIM potentially inappropriate medication, NSAIDs non-steroidal anti-inflammatory drugs, SIADH syndrome of inappropriate antidiuretic hormone secretion, SSRI selective serotonin reuptake inhibitor

\subsection{Polypharmacy and Prevalence of PIM}

The prevalence of both polypharmacy and PIM was comparable to findings in recent data from Switzerland [4] but higher than previous estimates $[3,9,10]$. Participants in our study were older than in previous studies $(>75$ years in our study vs. $>65$ years). Polypharmacy tends to increase with age, and many Beers criteria start to apply systematically at the age of 75 years (e.g. chronic use of NSAIDs, dabigatran or prasugrel) or 80 years (aspirin for primary prevention). Our study highlights the high prevalence of benzodiazepines, non-benzodiazepine/benzodiazepine receptor agonist hypnotics, specific cardiovascular drugs, oral non-cyclooxygenase-selective NSAIDs for chronic use and SSRIs. Important differences exist between previous studies conducted in Swiss patients and our study. For example, aspirin for primary prevention of cardiac events by patients aged $>80$ years and vasodilators were not reported in other claim-based studies, which do not have access to clinical information. By contrast, all these items were very common in our patient population, which may explain some of the differences in PIM prevalence [3, 10].

Among patients aged $\geq 75$ years followed in family medicine, important differences in prescription patterns were observed by sex/gender. Men received more cardiovascular prevention drugs, whereas women received more mineral supplements and antidepressants, despite a similar prevalence of cardiovascular or psychological conditions in men and women. Cardiovascular drugs were also less prescribed in women. While some of these differences may still reflect true diagnosis prevalence differences, further attention should be given to potential under- or overdiagnosis of specific conditions in older patients, based on well-documented medical gender bias $[15,25]$.

In contrast with previous studies in which older women were prescribed more PIMs [8, 12, 13], we did not identify 
major differences in overall PIM prevalence. However, the sex/gender differences we found in the type of PIMs echo the differences found in prescription patterns: women were more likely to have PIMs related to antidepressants, and men were more likely to have PIMs related to vasodilators. Larger studies exploring the reasons for increased or different PIMs in women hypothesise on multiple biological and social factors. Sex differences in the prevalence of conditions may explain discrepancies in drug prescriptions (and therefore the risk of PIM) and may imply a different navigation of the health system and the number of health providers involved (increasing the risk of PIMs). Social factors include gender bias in diagnosis and treatment for similar conditions and the intersection of gender with other social factors, such as education, living conditions, communication modes and healthcare provider-patient interactions [14, 19].

\subsection{Limitations of the Study}

Our analysis of potential inappropriateness was based solely on the Beers criteria. We included patients who consulted at least twice during the last year, which may have biased the sample towards patients who consult often and use more medication. Also, physicians participating in the cluster-randomised trial may not be fully representative of all Swiss physicians, although we tried to limit inclusion criteria as much as possible to align with the pragmatic nature of the trial. Some medical conditions (e.g. tobacco use, obesity) were only counted if listed in the medical file as a diagnosis, so may be underestimated. Creatinine clearance was not noted for patients with chronic kidney disease, which may have led to some NSAID use being misclassified as potentially inappropriate. Also, the distinction between primary and secondary prevention relied on the cardiovascular diagnoses mentioned in the medical file, which may also have been underreported. Overall, whereas we acknowledge the potential for misclassification for PIMs that require specific conditions, we believe the quality of the clinical information provided for these patients as part of an intervention trial to be better than that of routine health records or claims data. Finally, drug prescription is not equivalent to drug use, as patients may never start the prescribed drug or may stop it prematurely. This may have led to overestimation of polypharmacy but not the estimation of potentially inappropriate prescriptions considering that a drug not taken is still potentially inappropriately prescribed.

\subsection{Clinical Implications}

This study highlighted the existing challenges in the medication of older patients in Switzerland in terms of PIM and polypharmacy. Polypharmacy based on the number of medications is not necessarily inappropriate, considering that patients with several diagnoses and comorbidities may require multiple medications that may all be clinically indicated. However, the risk of PIMs increases with the number of prescribed drugs. Tools to reduce PIMs, such as the PRISCUS list [26], Beers criteria [6], the Screening Tool of Older People's Prescriptions (STOPP) and Screening Tool to Alert to Right Treatment (START) criteria [7], exist, but studies have shown that family physicians do not necessarily use them because of negative views [27]. Although physicians are aware of PIM and polypharmacy [27], medication they consider as potentially inappropriate does not necessarily match established criteria such as the PRISCUS list.

Interestingly, only a limited number of medication classes were involved in most PIMs. In this context, targeted information on the most prevalent PIM categories, for example PPIs, diuretics, benzodiazepines, and aspirin for primary prevention (Table 3), could be more efficient than lengthy deprescription lists. Including some deprescription advice in the 'top five' lists as promoted by the 'Choosing wisely' campaign is probably promising, but more effort is needed for these recommendations to be known to and applied by physicians [28]. Furthermore, prescription habits for specific drugs such as PPIs, NSAIDs, benzodiazepines and z-drugs must evolve to include limited treatment durations. We highlighted some differences in prescription habits by sex/gender, which suggested a need for physicians to reflect on their potential implicit gender biases in diagnosis and treatment. Indeed, targeted information on the most prevalent PIM categories, differentiating men and women, could be more efficient than lengthy deprescription lists. Such an approach should be further tested within deprescription trials.

\section{Conclusions}

Both polypharmacy and potentially inappropriate prescribing were very common in older patients followed in family medicine in Switzerland. Interestingly, only a limited number of medication classes were involved in most PIMs, and patterns varied by sex/gender. In this context, simple deprescription lists targeting the most frequently inappropriately prescribed drugs according to patient sex/gender could prove more useful than lengthy generic advice to reduce potentially inappropriate prescriptions.

\section{Compliance with Ethical Standards}

Conflict of Interest David Schnegg, Nicolas Senn, Olivier Bugnon, Joëlle Schwarz and Yolanda Mueller have no conflicts of interest that are directly relevant to the content of this article.

Ethical Approval All procedures performed in studies involving human participants were in accordance with the ethical standards of the cantonal research committee (CER-VD 2016-00422) and with the 1964 
Declaration of Helsinki and its later amendments or comparable ethical standards.

Informed Consent Informed consent was obtained from all individual participants included in the study.

Funding The AGE trial is funded by the Swiss National Science Foundation (Grand No. 32003B_159863/1).

Data Availability The datasets generated and/or analysed during the current study are available from the corresponding author on reasonable request.

Open Access This article is licensed under a Creative Commons Attribution-NonCommercial 4.0 International License, which permits any non-commercial use, sharing, adaptation, distribution and reproduction in any medium or format, as long as you give appropriate credit to the original author(s) and the source, provide a link to the Creative Commons licence, and indicate if changes were made. The images or other third party material in this article are included in the article's Creative Commons licence, unless indicated otherwise in a credit line to the material. If material is not included in the article's Creative Commons licence and your intended use is not permitted by statutory regulation or exceeds the permitted use, you will need to obtain permission directly from the copyright holder. To view a copy of this licence, visit https://creativecommons.org/licenses/by/4.0/.

\section{References}

1. Sirois C, Domingues NS, Laroche ML, Zongo A, Lunghi C, Guenette L, et al. Polypharmacy Definitions for multimorbid older adults need stronger foundations to guide research, clinical practice and public health. Pharmacy. 2019. https://doi.org/10.3390/ pharmacy7030126.

2. Midao L, Giardini A, Menditto E, Kardas P, Costa E. Polypharmacy prevalence among older adults based on the survey of health, ageing and retirement in Europe. Arch Gerontol Geriatr. 2018;78:213-20. https://doi.org/10.1016/j.archger.2018.06.018.

3. Blozik E, Rapold R, von Overbeck J, Reich O. Polypharmacy and potentially inappropriate medication in the adult, community-dwelling population in Switzerland. Drugs Aging. 2013;30(7):561-8. https://doi.org/10.1007/s40266-013-0073-0.

4. Schneider R, Reinau D, Schur N, Blozik E, Fruh M, Signorell A, et al. Drug prescription patterns, polypharmacy and potentially inappropriate medication in Swiss nursing homes: a descriptive analysis based on claims data. Swiss Med Wkly. 2019;149:w20126. https://doi.org/10.4414/smw.2019.20126.

5. Aubert CE, Streit S, Da Costa BR, Collet TH, Cornuz J, Gaspoz JM, et al. Polypharmacy and specific comorbidities in university primary care settings. Eur J Intern Med. 2016;35:35-42. https:// doi.org/10.1016/j.ejim.2016.05.022.

6. American Geriatrics Society 2015 Updated Beers Criteria for Potentially Inappropriate Medication Use in Older Adults. J Am Geriatr Soc. 2015;63(11):2227-46. https://doi.org/10.1111/ jgs.13702.

7. O'Mahony D, O'Sullivan D, Byrne S, O'Connor MN, Ryan C, Gallagher P. STOPP/START criteria for potentially inappropriate prescribing in older people: version 2. Age Ageing. 2015;44(2):213-8. https://doi.org/10.1093/ageing/afu145.

8. Sakr S, Hallit S, Haddad M, Khabbaz LR. Assessment of potentially inappropriate medications in elderly according to Beers 2015 and STOPP criteria and their association with treatment satisfaction. Arch Gerontol Geriatr. 2018;78:132-8. https://doi. org/10.1016/j.archger.2018.06.009.

9. Reich O, Rosemann T, Rapold R, Blozik E, Senn O. Potentially inappropriate medication use in older patients in Swiss managed care plans: prevalence, determinants and association with hospitalization. PLoS One. 2014;9(8):e105425. https://doi.org/10.1371/ journal.pone.0105425.

10. Riordan DO, Aubert CE, Walsh KA, Van Dorland A, Rodondi N, $\mathrm{Du}$ Puy RS, et al. Prevalence of potentially inappropriate prescribing in a subpopulation of older European clinical trial participants: a cross-sectional study. BMJ Open. 2018;8(3):e019003. https:// doi.org/10.1136/bmjopen-2017-019003.

11. Skoog J, Midlov P, Borgquist L, Sundquist J, Halling A. Can gender difference in prescription drug use be explained by gender-related morbidity?: a study on a Swedish population during 2006. BMC Public Health. 2014;14:329. https://doi. org/10.1186/1471-2458-14-329.

12. Nunez-Montenegro A, Montiel-Luque A, Martin-Aurioles E, Garcia-Dillana F, Krag-Jimenez M, Gonzalez-Correa JA. Evaluation of inappropriate prescribing in patients older than 65 years in primary health care. J Clin Med. 2019. https://doi.org/10.3390/ jem8030305.

13. Perez T, Moriarty F, Wallace E, McDowell R, Redmond P, Fahey $T$. Prevalence of potentially inappropriate prescribing in older people in primary care and its association with hospital admission: longitudinal study. BMJ. 2018;363:k4524. https://doi. org/10.1136/bmj.k4524.

14. Morgan SG, Weymann D, Pratt B, Smolina K, Gladstone EJ, Raymond $\mathrm{C}$, et al. Sex differences in the risk of receiving potentially inappropriate prescriptions among older adults. Age Ageing. 2016;45(4):535-42. https://doi.org/10.1093/ageing/afw074.

15. Hofer-Duckelmann C. Gender and polypharmacotherapy in the elderly: a clinical challenge. Handb Exp Pharmacol 2012;214:169-82. https://doi.org/10.1007/978-3-642-30726-3_9.

16. Brannstrom J, Hamberg K, Molander L, Lovheim H, Gustafson Y. Gender disparities in the pharmacological treatment of cardiovascular disease and diabetes mellitus in the very old: an epidemiological, cross-sectional survey. Drugs Aging. 2011;28(12):9931005. https://doi.org/10.2165/11594730-000000000-00000.

17. Schafers A, Martini N, Moyes S, Hayman K, Zolezzi M, McLean $\mathrm{C}$, et al. Medication use in community-dwelling older people: pharmacoepidemiology of psychotropic utilisation. J Prim Health Care. 2014;6(4):269-78.

18. Jasuja GK, Reisman JI, Weiner RS, Christopher ML, Rose AJ. Gender differences in prescribing of zolpidem in the Veterans Health Administration. Am J Manag Care. 2019;25(3):e58-65.

19. Johnell K, Weitoft GR, Fastbom J. Sex differences in inappropriate drug use: a register-based study of over 600,000 older people. Ann Pharmacother. 2009;43(7-8):1233-8. https://doi.org/10.1345/ aph.1M147.

20. Methodology. WCCfDS. ATC classification index with DDDs. Oslo. 2018. https://www.whocc.no/atc_ddd_index/(2019).

21. N'Goran AA, Blaser J, Deruaz-Luyet A, Senn N, Frey P, Haller $\mathrm{DM}$, et al. From chronic conditions to relevance in multimorbidity: a four-step study in family medicine. Fam Pract. 2016;33(4):43944. https://doi.org/10.1093/fampra/cmw030.

22. Masnoon N, Shakib S, Kalisch-Ellett L, Caughey GE. What is polypharmacy? A systematic review of definitions. BMC Geriatr. 2017;17(1):230. https://doi.org/10.1186/s12877-017-0621-2.

23. Hanlon JT, Schmader KE, Ruby CM, Weinberger M. Suboptimal prescribing in older inpatients and outpatients. J Am Geriatr Soc. 2001;49(2):200-9.

24. Phillips SP, Hamberg K. Doubly blind: a systematic review of gender in randomised controlled trials. Global Health Action. 2016;9:29597. https://doi.org/10.3402/gha.v9.29597. 
25. Regitz-Zagrosek V, Oertelt-Prigione S, Prescott E, Franconi F, Gerdts E, Foryst-Ludwig A, et al. Gender in cardiovascular diseases: impact on clinical manifestations, management, and outcomes. Eur Heart J. 2016;37(1):24-34. https://doi.org/10.1093/ eurheartj/ehv598.

26. Holt S, Schmiedl S, Thurmann PA. Potentially inappropriate medications in the elderly: the PRISCUS list. Dtsch Arztebl Int. 2010;107(31-32):543-51. https://doi.org/10.3238/arzte bl.2010.0543.

27. Pohontsch NJ, Heser K, Loffler A, Haenisch B, Parker D, Luck $\mathrm{T}$, et al. General practitioners' views on (long-term) prescription and use of problematic and potentially inappropriate medication for oldest-old patients - a qualitative interview study with GPs (CIM-TRIAD study). BMC Fam Pract. 2017;18(1):22. https://doi. org/10.1186/s12875-017-0595-3.

28. Selby K, Cornuz J, Cohidon C, Gaspoz JM, Senn N. How do Swiss general practitioners agree with and report adhering to a top-five list of unnecessary tests and treatments? Results of a cross-sectional survey. Eur J Gen Pract. 2018;24(1):32-8. https:// doi.org/10.1080/13814788.2017.1395018. 